Bond University

Research Repository

\title{
Optimizing Augmented Reality Outcomes in a Gamified Place Experience Application through Design Science Research
}

Vasilevski, Nikolche; Brand, Jeffrey E.; Birt, James R.

Published in:

VRCAI '19 Proceedings of the 17th International Conference on Virtual-Reality Continuum and its Applications in Industry

DOI:

$10.1145 / 3359997.3365747$

Licence:

Unspecified

Link to output in Bond University research repository.

Recommended citation(APA):

Vasilevski, N., Brand, J. E., \& Birt, J. R. (2019). Optimizing Augmented Reality Outcomes in a Gamified Place Experience Application through Design Science Research. In S. N. Spencer (Ed.), VRCAl'19 Proceedings of the 17th International Conference on Virtual-Reality Continuum and its Applications in Industry [52] Association for Computing Machinery (ACM). https://doi.org/10.1145/3359997.3365747

\section{General rights}

Copyright and moral rights for the publications made accessible in the public portal are retained by the authors and/or other copyright owners and it is a condition of accessing publications that users recognise and abide by the legal requirements associated with these rights.

For more information, or if you believe that this document breaches copyright, please contact the Bond University research repository coordinator. 


\section{Optimizing Augmented Reality Outcomes in a Gamified Place Experience Application through Design Science Research}

\author{
Nikolche Vasilevski \\ Faculty of Society and Design \\ Bond University, Gold Coast, \\ QLD, Australia, \\ nvasilev@bond.edu.au
}

\author{
Jeffrey Brand \\ Faculty of Society and Design \\ Bond University, Gold Coast, \\ QLD, Australia, \\ jbrand@bond.edu.au
}

\author{
James Birt \\ Faculty of Society and Design \\ Bond University, Gold Coast, \\ QLD, Australia \\ jbirt@bond.edu.au
}

\begin{abstract}
Nearly ubiquitous smartphone use invites research and development of augmented reality experiences promoting knowledge and understanding. However, there is a lack of design science research dissemination about developing these solutions. This paper adds to the information systems body of knowledge by presenting the second iteration of Design Science Research Methodology artefact and the process of its development in the form of a gamified place experience application about indigenous art, focusing on the optimization of AR integration and user interface enhancements. In testing the usability, we illustrate how the application was optimized for successful outcomes. The qualitative analysis results revealed the high level of usability of the mobile application leading to further testing of efficacy in creating Sense of Place where the art is curated and displayed.
\end{abstract}

\section{CCS CONCEPTS}

- Human-centered computing Mixed / augmented reality • Human-centered computing Empirical studies in ubiquitous and mobile computing

\section{KEYWORDS}

Sense of Place, Gamification, Service Marketing, AR, Tours

\section{ACM Reference format:}

Nikolche Vasilevski, Jeffrey Brand and James Birt. 2019. Optimizing Augmented Reality Outcomes in a Gamified Place Experience Application through Design Science Research. In Proceedings of VRCAI '19: The 17th International Conference on Virtual-Reality Continuum and its Applications in Industry (VRCAI '19), November 14-16, 2019, Brisbane, QLD, Australia. ACM, New York, NY, USA, 2 pages. https://doi.org/10.1145/3359997.3365747

Permission to make digital or hard copies of part or all of this work for personal or classroom use is granted without fee provided that copies are not made or distributed for profit or commercial advantage and that copies bear this notice and the full citation on the first page. Copyrights for third-party components of this work must be honored. For all other uses, contact the owner/author(s).

VRCAI '19, November 14-16, 2019, Brisbane, OLD, Australia

(C) 2019 Copyright held by the owner/author(s).

ACM ISBN 978-1-4503-7002-8/19/11.

https://doi.org/10.1145/3359997.3365747

\section{Introduction}

Augmented Reality (AR) and Gamification of places has been studied [Billinghurst et al., 2015, Vasilevski et al., 2018], highlighting the positive effect and the behavioral and the psychological outcomes that the implementations have on the players. However, AR Gamification as it relates to Sense of Place (SOP) and development optimization and communication requires more research [Vasilevski and Birt, 2019]. Design Science Research Methodology (DSRM) is an iterative methodology for the development of Information Systems (IS) applications. It is a process of systemically developing a solution to an identified problem, in the form of an artefact or multiple artefacts [Peffers et al., 2007]. The first DSRM iteration (I1) of the solution for this research is discussed in [Vasilevski and Birt, 2019], where the authors focused on the initial development and testing of an indigenous artwork narrated tour app. This paper presents the second iteration (I2) of the DSRM development process by answering the research question "How can developers optimize for successful AR outcomes?"

\section{Optimizing Artefact}

The mobile application developed in I1 (Figure 1) represents a solution to replicate a human tour guide at a display of indigenous artworks. In I1 we presented, the title and author anchored on the real-world paintings with computer-generated voice narration, limited to six artworks from the indigenous artwork tour. The major updates in I2 were the inclusion of 25 paintings, with new AR features enhancing both the story and the painting knowledge, and human voice narration to enhance the authenticity and the connection with the artworks.

The paintings were photographed under uniform light with a high-resolution camera. The photos were optimized following the Vuforia developers' guidelines; we used Vuforia plugin v7 and Unity 2018. Every image target was used as a separate game object with the features as $3 \mathrm{~d}$ models attached. We tested the app in-situ on various android and iOS devices. However, independent of the type of mobile device, the app was only able to identify $19 / 31$ targets. We identified two potential causes; First, the dim, non-uniform lightning affected the feature recognition. Second, the paintings were large, up to $4.5 \mathrm{~m}$ in diameter and within $2.5 \mathrm{~m}$ corridors, which caused viewing angle issues. We addressed the causes by sharpening the images, 
repositioning paintings, and cropping feature areas, leaving six unrecognizable paintings, or 25 in total included in the tour.
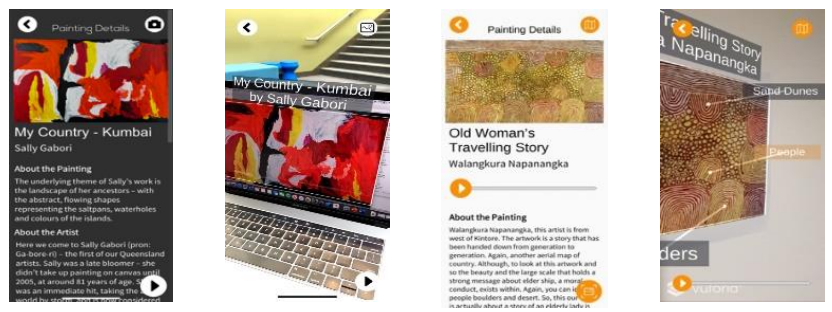

Figure 1: DSRM artefact, artefact, left (I1) right (I2).

We also focused on app usability and AR component responsiveness. By loading the targets at the app start, we improved the loading time of the AR scene, and the interface interactivity was improved by increasing the size of the collider for the ray-casted tap on the screen. Additional changes were also made to the menus, tour screens, gallery layout and colors to improve the user experience and lay the foundations for future DSRM iterations.

\section{Methodology}

The sample size of the testers for I2 was $(n=11)$, of which five were experts $(n=5)$, and six were undergraduate students $(n=6)$. The experts' group consisted of Indigenous culture expert, Userexperience expert, Service-marketing expert, SOP expert and Exhibit organization expert. The student sample represented the target user population. Both groups' use of the app was observed, and later they were interviewed, and their feedback recorded. The data gathered was in the form of observation notes and interview transcripts and notes. Testing was performed individually on an iPhone X smartphone. The experts tested app in-situ, while the students tested the app in a simulated environment, as part of an in-class activity. Both groups used over-ear headsets for the audio narration. After a short introduction of the app, we observed the testers using the app, followed by semi-structured interviews, conducted after the use.

Usability was assessed by the method used in [Vasilevski and Birt, 2019]: Aesthetic graphics, Color, Control obviousness, Entry point, Fingertip-size controls, Font, Gestalt, Hierarchy, Subtle animation, Transition. We also used the main AR evaluation techniques: Objective measurements, Subjective measurements, Qualitative analysis, Usability evaluation techniques and Informal evaluations [Billinghurst et al., 2015]. We used thematic analysis and the constructs and the guidelines described above, to code the interview transcripts and the field notes. The two emerged themes were: onboarding process and tapping on the painting features.

\section{Results, Discussion and Conclusion}

The observation and thematic analysis of semi-structured interviews from the usability testing, the results showed high user satisfaction and usability for the app v2. This is evident in the statements such as: "It works, and it works well, and it's easy to use." The added changes and new features were acclaimed by the experts and adopted by the student testers. The app stability was very high, and it did not freeze nor crash during the testing. We did not observe any significant negative effects.

The artwork design and graphics (aesthetic graphics) were very satisfactory, reflected in: "It's very clean..." and "very good photos of [the paintings]." All testers, except one, liked the color theme, by stating "I like it... Looks good." and "The orange is good." The contrast was also deemed satisfactory. The controls across the app were very consistent. The use of the app was obvious to the testers: "it's pretty easy to use. Pretty straightforward.", The audio progress bar was also appreciated. The app accessibility was also on a high level. Regarding the Fingertip-size controls, there were some concerns about the size of the check buttons on the Welcome screen, which proved to be challenging to tap on. The UX expert proposed to adjust the font color and weight on some screens to improve readability and the hierarchy. Font size resulted in contrasting opinions. The proximity and grouping of the interface elements (gestalt) were adequate for the application purpose. The app hierarchy was clear, and the structure of the app was recognized very quickly: "That's logical... it's all really self-explanatory." The animations were used appropriately and effectively. The transitions and the flow of the interface elements were meaningful and easy to follow. Half of the testers felt an onboarding process was needed to explain the app capabilities and the features before the start of the tour. Some of the testers proposed taping on the painting features within the $A R$ screen that will take the user to the painting text or offer more info about the feature.

The DSRM outcome is one or multiple artefacts as a solution to a problem, which in this study is to develop an application useful for gamified SOP experiences. The importance of this research is to show how artefacts are produced under DSRM, to develop the literature in this area. We contribute to the information systems field, by proposing one verified procedure to successful AR outcome in relation to speed, location and interface optimization, by listening to the users and using usercentered design practice. This paper concludes the second iteration of the DSRM process as it disseminates the acquired knowledge. Finally, I2 outcome artefact is the app v2 as a highly usable and successful implementation of the AR component. Further research will iterate the gamification component.

\section{REFERENCES}

Billinghurst, M., Clark, A. and Lee, G. (2015). A Survey of Augmented Reality. Foundations and Trends ${ }^{\circledR}$ in Human-Computer Interaction 8, 2-3, 73-272. http://dx.doi.org/10.1561/1100000049

Peffers, K., Tuunanen, T., Rothenberger, M. A. and Chatterjee, S. (2007). A Design Science Research Methodology for Information Systems Research. Journal of management information systems $24, \quad 3, \quad 45-77$. http://dx.doi.org/10.2753/MIS0742-1222240302

Vasilevski, N. and Birt, J. (2019). Towards Optimizing Place Experience Using Design Science Research and Augmented Reality Gamification. In Proceedings of 12th Australasian Simulation Congress. Springer Singapore, 77-92. http://dx.doi.org/10.1007/978-981-32-9582-7_6

Vasilevski, N., Brand, J. and Birt, J. (2018). Analysing Micro-Location Beacon Gamification: Scenarios, Types and Characteristics. In Proceedings of Proceedings of the 30th Australian Conference on Computer-Human $\begin{array}{llll}\text { Interaction. } & \mathrm{ACM}, & \text { New } & \text { York, }\end{array}$ http://dx.doi.org/10.1145/3292147.3292210 